\title{
Natural Course of Allergic and Nonallergic Rhinitis After 2 Years in Korean Children
}

\author{
Seung-Hoon Lee ${ }^{1, *} \cdot$ Ji Ho Choi ${ }^{2, *} \cdot$ Jeffrey D. Suh ${ }^{3} \cdot$ Sochung Chung ${ }^{4} \cdot$ Seok-Chan Hong ${ }^{5}$ Jin Kook Kim · Jae Hoon Cho \\ ${ }^{1}$ Department of Otorhinolaryngology-Head and Neck Surgery, Korea University Ansan Hospital, Korea University College of Medicine, Ansan, \\ Korea; ${ }^{2}$ Department of Otorhinolaryngology-Head and Neck Surgery, Soonchunhyang University Bucheon Hospital, Soonchunhyang University \\ College of Medicine, Bucheon, Korea, ${ }^{3}$ Department of Head and Neck Surgery, UCLA School of Medicine, Los Angeles, CA, USA; Departments \\ of ${ }^{4}$ Pediatrics and ${ }^{5}$ Otorhinolaryngology-Head and Neck Surgery, Konkuk University School of Medicine, Seoul, Korea
}

Objectives. Allergic and nonallergic rhinitis are very common disease for children, however, little is known about their natural courses in the general population. The purpose is to evaluate the natural course of allergic and nonallergic rhinitis in children.

Methods. We analyzed data from Snoring Child Cohort of 178 children (107 boys and 71 girls). All children entered the study at the age of 7 years (range, 6.5 to 7.4 years). Questionnaires regarding chronic rhinitis, a skin prick test (SPT) for 5 inhalent allergens, and specific IgE for 2 dust mites were administered. Children were classified into 4 groups: allergic rhinitis (rhinitis, positive SPT), nonallergic rhinitis (rhinitis, negative SPT), sensitization only (no rhinitis, positive SPT), and control (no rhinitis, negative SPT). We repeated follow them annually, and analyzed the data of first and third year for this study.

Results. Finally, the data of 122 children were analyzed. Among 18 children with allergic rhinitis at 7 years, 13 (72\%) became sensitization only after 2 years and $5(28 \%)$ were remained having allergic rhinitis. Five out of 19 children $(26 \%)$ with nonallergic rhinitis developed into allergic rhinitis and $7(37 \%)$ into control at 9 years. Twenty-four out of 28 children $(86 \%)$ with sensitization only at 7 years remained the same at 9 years. Among 57 control children at 7 years, 2 (4\%) developed into allergic rhinitis, $7(12 \%)$ with nonallergic rhinitis, and $16(28 \%)$ with sensitization only at 9 years.

Conclusion. The status of chronic rhinitis and allergen sensitization is ever-changing in children.

Keywords. Rhinitis; Rhinitis, Allergic; Allergens; Child

\section{INTRODUCTION}

Chronic rhinitis in children is a very common disease [1]. It is generally not considered to be severe, however, it worsens the

\footnotetext{
- Received July 10, 2015

Revised September 15, 2015

Accepted November 17, 2015

- Corresponding author: Jae Hoon Cho

Department of Otorhinolaryngology-Head and Neck Surgery, Konkuk

University Medical Center, Konkuk University School of Medicine, 120-1

Neungdong-ro, Gwangjin-gu, Seoul 05030, Korea

Tel: +82-2-2030-7667, Fax: +82-2-2030-5299

E-mail: jaehoon@kuh.ac.kr

*The first two authors contributed equally to this study.
}

children's life quality, school performance, physical health, growth, sleep, and etc. [2]. Chronic rhinitis can be classified into allergic and nonallergic rhinitis [3]. Allergic rhinitis is caused by an IgE-mediated reaction, while the pathophysiology of nonallergic rhinitis is still ambiguous [3]. Most studies regarding chronic rhinitis have focused on allergic rhinitis, however, nonallergic rhinitis is also prevalent and should be focused on more $[3,4]$.

The symptomatic and physical distinction between allergic and nonallergic rhinitis is difficult [5]. For the exact differential diagnosis, allergy tests including the skin prick test or the measurement of specific IgE is essential [3-5]. It is believed that a positive test results into allergic rhinitis whereas negative results

Copyright (C) 2016 by Korean Society of Otorhinolaryngology-Head and Neck Surgery.

This is an open-access article distributed under the terms of the Creative Commons Attribution Non-Commercial License (http://creativecommons.org/licenses/by-nc/4.0)

which permits unrestricted non-commercial use, distribution, and reproduction in any medium, provided the original work is properly cited. 
are determined to be nonallergic rhinitis, and that once the diagnosis is settled, it is persistent for a long time [3-5]. However, it is known that the status of sensitization for allergens could change over time and that rhinitis symptom also could disappear without any specific reason [6,7]. Authors thought that it is very important to grasp these changes to better understand allergic and nonallergic rhinitis. Though, few longitudinal studies have evaluated the changes seen in allergic and nonallergic rhinitis, especially among Asian children.

The purpose of this study was to evaluate the changes seen in allergic and nonallergic rhinitis in Korean children using a prospective cohort.

\section{MATERIALS AND METHODS}

\section{Study design}

Data from the single prospective cohort 'Snoring Children Study' was analyzed. Originally, the study was designed to evaluate the effect of snoring on children in various perspectives. It encompassed a wide range of evaluations about general status, sleep pattern, behavior, stress level, and dietary life through questionnaire. It also involved body measurement, skin prick test, and blood tests for liver and thyroid function, growth hormone, specific IgE for dust mites, complete blood count, insulin, glucose, hemoglobin A1c, and so on. We enrolled all 178 first grade children (107 boys and 71 girls) from a public elementary school in Seoul, Korean, and evaluated them annually from 2012 to 2014. We will follow them up 2 years more. The detailed study design was described in our previous study [8]. For this study, the data collected between 2012 and 2014 was used.

On average, the children were 7 years old (range, 6.5 to 7.5 years) in 2012 and 9 years old (range, 8.5 to 9.5 years) in 2014 . Medications were not allowed for 2 weeks prior to this study. The skin prick test (SPT) was done for five most common allergens for Korean children, namely Dermatophagoides pteronyssinus, Dermatophagoides farina, cat, dog, and pollen mixture

\section{H I G H L I G H T S}

- We analyzed natural course of allergic and nonallergic rhinitis after 2 years based on 122 children.

- Among 18 children with allergic rhinitis at 7 years, 13 (72\%) became sensitization only after 2 years.

- Five out of 19 children (26\%) with nonallergic rhinitis developed into allergic rhinitis and 7 (37\%) into control at 9 years.

- Among 57 control children at 7 years, 2 (4\%) developed into allergic rhinitis, 7 (12\%) with nonallergic rhinitis, and $16(28 \%)$ with sensitization only at 9 years.
Table 1. Definition of allergic rhinitis, nonallergic rhinitis, sensitization only, and control

\begin{tabular}{lc}
\hline Classification & Definition \\
\hline Allergic rhinitis & $\begin{array}{c}\text { When child had chronic rhinitis and showed positive } \\
\text { skin prick test for at least one or more allergens. }\end{array}$ \\
Nonallergic rhinitis & $\begin{array}{c}\text { When child had chronic rhinitis, but did not show } \\
\text { any positive skin prick test for all allergens. }\end{array}$ \\
Sensitization only & $\begin{array}{c}\text { When child did not have chronic rhinitis, but showed } \\
\text { positive skin prick test for at least one or more } \\
\text { allergens. }\end{array}$ \\
Control & $\begin{array}{c}\text { When child neither had chronic rhinitis, nor showed } \\
\text { any positive skin prick test for all allergens. }\end{array}$ \\
\hline
\end{tabular}

(Allergy Therapeutics, Worthing, UK) [9]. If the wheal was larger than $3 \mathrm{~mm}$ or the histamine control, it was defined to be a positive SPT. Venous blood sampling was taken to measure specific IgE of D. pteronyssinus and D. farina (ImmunoCAP system, Phadia AB, Uppsala, Sweeden). IgE levels above $0.7 \mathrm{kU} / \mathrm{L}$ was defined as positive. The parents or guardian were surveyed using questionnaires about rhinitis-related symptoms according to the International Study of Asthma and Allergy in Children [1]. Chronic rhinitis was defined if children had a sneezing/runny nose or a blocked nose in the last 3 months without the diagnosis of the common cold. We classified the children based on the presence or absence of chronic rhinitis and their SPT results in Table 1. The result of ImmunoCAP was not considered for this classification.

This study was approved by the Institutional Review Board of Konkuk University Hospital (KUH1110015) and registered in Clinical Research Information Service (KCT0000699). A written informed consent was acquired from the children's parents prior to enrolling in the study.

\section{Data analysis}

The prevalence of allergic rhinitis, nonallergic rhinitis, sensitization only, and control from the data of 2012 and 2014 was calculated. The change of sensitization for 5 allergens from the skin prick test results and for 2 allergens from the ImmunoCAP data was also analyzed.

\section{RESULTS}

Finally, the data of 122 children (75 boys and 47 girls) was analyzed for this study. Baseline characteristics like sex, physical measurements, or parental history of allergic rhinitis did not differ between the children included in this study and the rest of cohort children (data not shown).

Prevalence of allergic rhinitis, nonallergic rhinitis, sensitization only, and control

The prevalence of allergic ( $14.8 \%$ to $11.5 \%)$ and nonallergic rhinitis $(15.6 \%$ to $9.8 \%$ ) decreased over the course of 2 years, 
while those of sensitization only ( $23.0 \%$ to $45.1 \%)$ increased. The result is summarized in Table 2 .

\section{Analysis of transition from 7 to 9 years}

Among 18 children with allergic rhinitis at the age of 7, 13 $(72 \%)$ became sensitization only after 2 years and $5(28 \%)$ remained as allergic rhinitis. None of them developed into nonallergic rhinitis. On the other hand, 5 out of $19(26 \%)$ with nonallergic rhinitis at 7 years, turned into allergic rhinitis at 9 years and $7(37 \%)$ into control. Twenty-four out of 28 children $(86 \%)$ who started with sensitization only remained the same until 9 years where only $2(7 \%)$ developed into allergic rhinitis. Among the 57 control children at the start, $2(4 \%)$ converted into allergic rhinitis, 7 (12\%) with nonallergic rhinitis, and $16(28 \%)$

Table 2. Prevalence of allergic rhinitis, nonallergic rhinitis, sensitization only, and control at 7 and 9 years

\begin{tabular}{lcc}
\hline Variable & 7 Years $(n=122)$ & 9 Years $(n=122)$ \\
\hline Allergic rhinitis & $18(14.8)$ & $14(11.5)$ \\
Nonallergic rhinitis & $19(15.6)$ & $12(9.8)$ \\
Sensitization only & $28(23.0)$ & $55(45.1)$ \\
Control & $57(46.7)$ & $41(33.6)$ \\
Total & $122(100)$ & $122(100)$ \\
\hline
\end{tabular}

Values are presented as number (\%). with sensitization only at 9 years. All of these data are summarized in Table 3.

\section{Transition of sensitization based on skin prick test}

The prevalence of sensitization at 7 years was $27.9 \%$ for $D$. pteronyssinus, $36.1 \%$ for $D$. farina, $2.5 \%$ for cats, $3.3 \%$ for dogs, and $0.8 \%$ for mixed pollens. The prevalence profoundly increased at 9 years of age for all the 5 allergens, especially for the cat, dog, and mixed pollen. The conversion from sensitization at 7 years to nonsensitization at 9 years occurred in 8 out of 86 cases (9\%). Among the 167 sensitized cases at 9 years, 89 cases $(53 \%)$ were newly sensitized. The result is summarized in Table 4.

\section{Transition of sensitization based on ImmunoCAP}

The prevalence of sensitization at 7 years was $41.0 \%$ for $D$. pteronyssinus and $47.5 \%$ for $D$. farina. The prevalence was nearly same at 9 years both allergens. However, 11 out of 50 sensitized cases $(22 \%)$ were conversed to nonsensitized after 2 years for $D$. pteronyssinus and 11 cases were newly sensitized. For D. farina, 6 out of 58 sensitized cases $(10 \%)$ were conversed to nonsensitized ones while 8 cases were newly sensitized. The result is summarized in Table 5 .

Table 3. Transition of allergic rhinitis, nonallergic rhinitis, sensitization only, and control after 2 years $(n=124)$

\begin{tabular}{lcccc}
\hline \multirow{2}{*}{7 Years } & \multicolumn{4}{c}{9 Years } \\
\cline { 2 - 5 } & Allergic rhinitis & Nonallergic rhinitis & Sensitization only & Control \\
\hline Allergic rhinitis $(n=18)$ & $5(28)$ & - & $13(72)$ & - \\
Nonallergic rhinitis $(n=19)$ & $5(26)$ & $5(26)$ & $2(11)$ & $7(37)$ \\
Sensitization only $(n=28)$ & $2(7)$ & - & $24(86)$ & $2(7)$ \\
Control $(n=57)$ & $2(4)$ & $7(12)$ & $16(28)$ & $34(60)$ \\
Total $(n=124)$ & $14(11)$ & $12(10)$ & $55(45)$ & $41(33)$ \\
\hline
\end{tabular}

Values are presented as number (\%).

Table 4. Transition of sensitization based on skin prick test result

\begin{tabular}{|c|c|c|c|c|c|}
\hline \multirow{2}{*}{ Allergen } & \multirow{2}{*}{$\begin{array}{c}7 \text { Years }(n=122) \\
\text { Sensitized }\end{array}$} & \multicolumn{4}{|c|}{9 Years $(n=122)$} \\
\hline & & Persistently sensitized & Newly sensitized & Total & Conversion to nonsensitized \\
\hline Dermatophagoides pteronyssinus & $34(27.9)$ & 33 & 24 & $57(46.7)$ & 1 \\
\hline Dermatophagoides farina & $44(36.1)$ & 42 & 17 & $59(48.4)$ & 2 \\
\hline Cat & $3(2.5)$ & 1 & 18 & $19(15.6)$ & 2 \\
\hline Dog & $4(3.3)$ & 1 & 14 & $15(12.3)$ & 3 \\
\hline Mixed pollens & $1(0.8)$ & 1 & 16 & $17(13.9)$ & 0 \\
\hline
\end{tabular}

Values are presented as number (\%) or number.

Table 5. Transition of sensitization based on ImmunoCAPa) result

\begin{tabular}{|c|c|c|c|c|c|}
\hline \multirow{2}{*}{ Allergen } & \multirow{2}{*}{$\begin{array}{c}7 \text { Years }(n=122) \\
\text { Sensitized }\end{array}$} & \multicolumn{4}{|c|}{9 Years $(n=122)$} \\
\hline & & Persistently sensitized & Newly sensitized & Total & Conversion to nonsensitized \\
\hline Dermatophagoides pteronyssinus & $50(41.0)$ & 39 & 11 & $50(41.0)$ & 11 \\
\hline Dermatophagoides farina & $58(47.5)$ & 50 & 8 & $58(47.5)$ & 6 \\
\hline
\end{tabular}

Values are presented as number (\%) or number.

a)ImmunoCAP system, Phadia AB, Uppsala, Sweeden. 


\section{DISCUSSION}

Briefly, we can summarize several characteristic findings from this study as following: (1) the prevalence of allergic rhinitis and nonallergic rhinitis decreased from 7 to 9 years, while those who are sensitized to allergen increased; (2) for those with allergic rhinitis at 7 years, approximately $70 \%$ became nonsymptomatic after 2 years; (3) for those with nonallergic rhinitis at 7 years, about $45 \%$ became nonsymptomatic while $25 \%$ developed into allergic rhinitis after 2 years; (4) nearly $90 \%$ of children with sensitization only remained with the sensitized status without rhinitis after 2 years; (5) the conversion rate from sensitization to nonsensitization for D. pteronyssinus and D. farina was very low (less than 5\%) based on the skin prick test, whereas the conversion was more commonly detected (about $10 \%$ to $20 \%$ ) by ImmunoCAP.

Thus far, we classify rhinitis only into allergic or nonallergic rhinitis [3]. Once the diagnosis is settled, we consider that it is persistent for a long time. However, this study showed that natural course of rhinitis is very dynamic. A birth cohort study of 2,024 Finland children by Westman et al. [10] also showed that the status of allergen sensitization and rhinitis classification had been changed quite a bit from 4 to 8 years old. For allergic rhinitis children at 4 years, $11.2 \%$ of them lost their rhinitis symptom in 4 years. While for nonallergic rhinitis ones, $65.2 \%$ lost their symptom. Among children with sensitization only, 56.3\% were classified as allergic rhinitis patients 4 years later. Among children with no rhinitis and no sensitization, $3.8 \%$ became allergic rhinitis patients, $5.8 \%$ nonallergic rhinitis, and $9.7 \%$ sensitization only in 4 years.

Considering the differences between the 2 studies including design, population, or follow-up period, several distinctive dissimilarities was observed. First, our study showed that rhinitis symptoms disappeared among over $70 \%$ of allergic rhinitis children in 2 years while the study by Westman et al. [10] did that only $12 \%$ of allergic rhinitis children lost rhinitis symptom in 4 years. We could not suggest any specific explanation for this difference, but both studies inferred that the higher proportion of children with allergic rhinitis could be spontaneously resolved than we had thought. Second, the conversion rate from nonallergic rhinitis to allergic rhinitis was reported to being only $5.6 \%$ by Westman et al. [10], while our study showed $26.3 \%$. Other studies also showed similar conversion rate with ours, ranging from $24 \%$ to $40 \%$ [6,7]. Thirdly, the conversion rate from sensitization only to allergic rhinitis was fully $56.3 \%$ by Westman et al. [10], while only $7.1 \%$ in our study. They argued that their study had demonstrated that sensitization to an allergen precedes the appearance of rhinitis symptoms [10]. However, other studies including ours have showed that nonallergic rhinitis becomes allergic rhinitis frequently, suggesting the symptomatic appearance precedes allergen sensitization [6,7].

Recently, rhinitis is regarded as syndrome or a group of vari- ous phenotypes, not a simply allergic or nonallergic rhinitis [11]. Numerous evidence have shown that drug responses, natural course, or prognosis varies among the same allergic or nonallergic rhinitis patients [3]. If we could define a phenotype or endotype of rhinitis more specifically, personalized treatment can be provided with the ability to predict the prognosis more accurately. As of now, more detailed classification for rhinitis is not available, so we need to diagnose patients repeatedly especially when the disease character looks changed.

We have to admit that this study has some limitations. To mention, the sample size was too small to show more definite conclusion. Therefore, showing the approximate outline of change instead of inferential statistical analysis was carried out. Second, we did not take any physical examinations of the nose to diagnosis rhinitis as questionnaires were solely used. Therefore, we could not identify the other causes of nasal obstruction like adenoid vegetation. Third, the follow-up period was only 2 years. However, as they are still currently being followed, there will be a future report with the results of a longer follow-up period.

In conclusion, the status of chronic rhinitis and allergen sensitization is ever-changing in children. Therefore, careful follow-up with repeated allergy tests are required when their rhinitis symptom changes.

\section{CONFLICT OF INTEREST}

No potential conflict of interest relevant to this article was reported.

\section{ACKNOWLEDGMENTS}

This research was supported by Basic Science Research Program through the National Research Foundation of Korea (NRF) funded by the Ministry of Education, Science and Technology (2011-0022916), Republic of Korea.

\section{REFERENCES}

1. Strachan D, Sibbald B,Weiland S, Ait-Khaled N,Anabwani G, Anderson HR, et al. Worldwide variations in prevalence of symptoms of allergic rhinoconjunctivitis in children: the International Study of Asthma and Allergies in Childhood (ISAAC). Pediatr Allergy Immunol. 1997 Nov;8(4):161-76.

2. Tharpe CA, Kemp SF. Pediatric allergic rhinitis. Immunol Allergy Clin North Am. 2015 Feb;35(1):185-98.

3. Bousquet J, Khaltaev N, Cruz AA, Denburg J, Fokkens WJ, Togias A, et al. Allergic Rhinitis and its Impact on Asthma (ARIA) 2008 update (in collaboration with the World Health Organization, GA(2) LEN and AllerGen). Allergy. 2008 Apr;63 Suppl 86:8-160.

4. Sin B, Togias A. Pathophysiology of allergic and nonallergic rhinitis. Proc Am Thorac Soc. 2011 Mar;8(1):106-14. 
5. Kalpaklioglu AF, Kavut AB. Allergic and nonallergic rhinitis: can we find the differences/similarities between the two pictures? J Asthma. 2009 Jun;46(5):481-5.

6. Rondon C, Dona I,Torres MJ, Campo P, Blanca M. Evolution of patients with nonallergic rhinitis supports conversion to allergic rhinitis. J Allergy Clin Immunol. 2009 May;123(5):1098-102.

7.Veskitkul J,Vichyanond P,Visitsunthorn N, Jirapongsananuruk O.The development of allergic rhinitis in children previously diagnosed as nonallergic rhinitis. Am J Rhinol Allergy. 2013 Jan;27(1):43-7.

8. Shin DH, Hong SC, Kim YW, Suh JD, Chung S, Lee SH, et al. Comprehensive comparison between snoring and non-snoring children. Korean J Otorhinolaryngol-Head Neck Surg. 2015 Mar;58(3):187-
92.

9. Kim YH, Yu BJ, KimWJ, Kim JE, Lee GH, Lee KA, et al. Correlation between skin prick test and MAST-immunoblot results in patients with chronic rhinitis. Asian Pac J Allergy Immunol. 2013 Mar;31(1): 20-5.

10. Westman M, Stjarne P, Asarnoj A, Kull I, van Hage M, Wickman M, et al. Natural course and comorbidities of allergic and nonallergic rhinitis in children. J Allergy Clin Immunol. 2012 Feb;129(2):403-8.

11. Giavina-Bianchi P. Defining phenotypes in rhinitis: a step toward personalized medicine. J Allergy Clin Immunol. 2015 Jan;135(1): $151-2$. 